\section{Regards sur l'économie allemande}

Bulletin économique du CIRAC

$72 \mid 2005$

Varia

\title{
Réforme du modèle allemand
}

SIEBERT Horst, Jenseits des sozialen Marktes. Eine Notwendige Neuorientierung der deutschen Politik / SPETH Rudolf, Die politischen Strategien der Initiative Neue Soziale Marktwirtschaft / Vision Deutschland. Der Wohlstand hat Zukunft

\section{OpenEdition}

\section{Journals}

Édition électronique

URL : http://journals.openedition.org/rea/308

DOI : $10.4000 /$ rea.308

ISBN : 978-2-8218-0840-9

ISSN : 1965-0787

Éditeur

CIRAC

Édition imprimée

Date de publication : 1 juillet 2005

ISSN : 1156-8992

Référence électronique

"Réforme du modèle allemand », Regards sur l'économie allemande [En ligne], 72 | juillet 2005,

document 3, mis en ligne le 24 avril 2008, consulté le 22 septembre 2020. URL : http://

journals.openedition.org/rea/308 ; DOI : https://doi.org/10.4000/rea.308

Ce document a été généré automatiquement le 22 septembre 2020.

(c) CIRAC 


\title{
Réforme du modèle allemand
}

\author{
SIEBERT Horst, Jenseits des sozialen Marktes. Eine Notwendige \\ Neuorientierung der deutschen Politik / SPETH Rudolf, Die politischen \\ Strategien der Initiative Neue Soziale Marktwirtschaft / Vision \\ Deutschland. Der Wohlstand hat Zukunft
}

\section{RÉFÉRENCE}

SIEBERT Horst, Jenseits des sozialen Marktes. Eine Notwendige Neuorientierung der deutschen Politik, Deutsche Verlags-Anstalt, Munich, 2005, 540 p. SPETH Rudolf, Die politischen Strategien der Initiative Neue Soziale Marktwirtschaft, Arbeitspapier n 96, Hans-Böckler-Stiftung, Düsseldorf, 2004, 40 p. Vision Deutschland. Der Wohlstand hat Zukunft, Coll. IW-Studien de l'Institut der deutschen Wirtschaft, Deutscher Instituts-Verlag, Cologne, 2005, 296 p.

1 L'Etat social allemand a présumé de ses moyens, expliquait en substance le président de la République fédérale voici quelques temps. Le manque de dynamisme économique de l'Allemagne est dû en grande partie à l'hypertrophie de son Etat social. Pour le dire autrement : l'équilibre entre les forces du marché et le champ social s'est détérioré. Les réformes que doit entreprendre l'Allemagne de son modèle économique et social ne peuvent s'appréhender séparément: elles sont indissociablement liées. C'est ce que rappelle dans un remarquable ouvrage destiné au grand public l'économiste Horst Siebert, qui fut durant 12 ans membre du Conseil des Sages. Il passe en revue les principaux problèmes : d'une trop forte régulation des marchés de produits à une trop forte ingérence de l'Etat dans le jeu de la concurrence, le défi du vieillissement démographique, les politiques trop timorées en matière de technologies du futur ou le trop faible investissement dans la qualification du capital humain. Et il propose un remède : il faut à l'Allemagne un big bang, une « refondation radicale de son économie de marché - par-delà le marché social ».

2 L'Institut der deutschen Wirtschaft (IW), un institut de recherches économiques proche de la fédération de l'industrie BDI, propose pour sa part une Vision Deutschland au soustitre évocateur: «La prospérité a un avenir ». L'IW se situe là dans la continuité de 
Ludwig Erhard, le père du "miracle économique ", qui avait publié au début des années 1950 un ouvrage intitulé Wohlstand für alle («La prospérité pour tous ») pour diffuser dans une large opinion les principes au fondement de sa politique de renouveau. L'ouvrage, destiné aux économistes, et qui comprend une analyse comparée des réformes menées en Grande-Bretagne, en Suède, aux USA et en Allemagne (depuis 1982), établit une série de propositions de réformes destinées au gouvernement fédéral. L'ouvrage, dont il existe aussi une version grand public éditée sous forme de brochure, a bénéficié du soutien de l'Initiative Neue Soziale Marktwirtschaft - INSM (www.chancenfueralle.de). Il s'agit d'un think tank organisé en réseau, rassemblant de nombreuses personnalités des domaines économique et social, et dont les travaux sont largement relayés dans l'opinion grâce à l'agence publicitaire Scholz \& Friends.

3 Créé à l'initiative de la fédération patronale de la métallurgie Gesamtmetall, l'INSM dont l'objectif premier est de convaincre l'opinion en expliquant clairement les enjeux des réformes nécessaires a particulièrement intéressé la Fondation Hans-Böckler, le centre de recherche du syndicalisme, qui lui consacre une étude. Certes, affirme l'introduction de ce portrait fouillé de l'Initiative, « les syndicats ne sont pas son adversaire désigné; mais ils le deviennent indirectement par le biais des thématiques soulevées ». Et pour mieux cerner 'l'adversaire' patronal, l'auteur de l'étude, spécialiste de la communication politique, détaille les stratégies de communication menées l'INSM (sans obédience particulière, il faut le relever), dévoilant accessoirement les modes de fonctionnement de la formation de l'opinion dans l'espace public allemand. (ib) 